Conclusion The most prevalent abnormal geometry type was eccentric hypertrophy that was present in $9,6 \%$ of controls but in $41,3 \%$ of obese children $(\mathrm{p}<0.05)$.

\section{PO-0040 WITHDRAWN}

\section{P0-0041 IS ECHOCARDIOGRAPHY AN ESSENTIAL TOOL IN MECHANICALLY VENTILATED CRITICALLY ILL CHILDREN: WHERE DO WE STAND IN TRAINING OF PAEDIATRIC INTENSIVISTS TO PERFORM BEDSIDE ECHOCARDIOGRAPHY?}

S Sahin, G Ayar, M Uysal Yazici, A Oden Akman. Pediatric Intensive Care Unit, Ankara Child Health Hematology Oncology Education and Research Hospital, Ankara, Turkey

\subsection{6/archdischild-2014-307384.716}

Objective To determine the indication and need for echocardiographic assessment according to clinical severity of patients and therapeutic interventions performed after echocardiographic evaluation in critically ill children.

Design Prospective observational study.

Setting 14-bed, tertiary care Paediatric Intensive Care Unit (PICU).

Methods The PICU is a multidisciplinary referral centre. A total of 140 children; 75 mechanically ventilated (MV) and 65 spontaneously breathing (SB) who were admitted to our unit consecutively from March to August 2013 were included into the study. The indication for echocardiography and therapeutic interventions performed after cardiology consultation were recorded. For the estimation of severity of disease the paediatric risk of mortality score (PRISM) III was determined. The correlation between Prism III score and the need for echocardiographic evaluations were analysed.

Results Ages of all patients were between 45 days to 18 years. The male-female ratio was 1.33 . Echocardiography was indicated in $88 \%(\mathrm{n}=66)$ of $\mathrm{MV}$ and $\% 46.2(\mathrm{n}=30)$ of SB patients. In $35.4 \%(n=34)$ of patients who underwent echocardiographic evaluation no definitive change occured in treatment strategy while in $64.6 \%(n=62)$ of patients decisive/supplemental information was obtained. Echocardiographic evaluation was necessary in MV children $(p<0.001)$ when compared with SB group and there was a positive correlation between Prism III score and the need for echocardiographic evaluation.

Conclusion Echocardiographic evaluation is essential in mechanically ventilated children and the need for echocardiographic assesment increases according to clinical severity of patients. Basic training for intensivists in this technique is challenging and needs to be developed and supported in critically ill children.

\section{PO-0042 PREVALENCE AND OUTCOME OF DIASTOLIC DYSFUNCTION IN CHILDREN WITH FLUID REFRACTORY SEPTIC SHOCK - A PROSPECTIVE OBSERVATIONAL STUDY}

J Sankar, A Jain, S Dewangan, N Dubey, R Das. Pediatrics, Pgimer Dr Rml Hospital, New Delhi, India

\subsection{6/archdischild-2014-307384.717}

Background and aims Severe sepsis is often characterised by disturbances in cardiac function, popularly known as sepsis induced myocardial dysfunction (SIMD). SIMD may be systolic (SD), diastolic (DD) or global. Diastolic dysfunction has been infrequently reported in only a few studies on adult patients till date. Detecting DD early in the course has important therapeutic and prognostic implications in the management of septic shock. Our aim was therefore, to determine the prevalence and outcome of DD in children with septic shock and to generate evidence for possible early clinical predictors of DD in such patients.

Methods Consecutive children $\leq 17$ years of age with fluid refractory septic shock and not on mechanical ventilation admitted to our ICU from June 2011 to August 2012 were included. $\mathrm{DD}$ was defined as an abnormal ' $\mathrm{E}$ ', mitral annulus velocity on tissue Doppler imaging at admission.

Results A total of 56 children were included. The prevalence of DD was $41.1 \%$ (95\% CI: 27.8 to 54.4$)$ and the mortality rate was $43 \%$ in those with DD. On univariable analysis of possible early predictors of $\mathrm{DD}$, we observed that children with $\mathrm{DD}$ tended to have higher mean CVP (13 vs. 6; p < 0.0001) and greater positivity for cTnT $(70 \%$ vs. $36 \%, \mathrm{p}=0.01)$ as compared to others. On multivariable analysis, only an increased CVP remained significant (adjOR: 1.6; 95\% CI: 1.12, 2.14, $\mathrm{p}=$ 0.008).

Conclusion Diastolic dysfunction is common in children with fluid refractory septic shock and immediate outcome may be poorer in such patients. Increased CVP after initial fluid resuscitation may be an early indicator of DD and warrant urgent bedside echocardiography.

\section{PO-0043 CLASSIC INFANTILE-ONSET POMPE DISEASE: A STUDY OF 8 CASES}

${ }^{1} \mathrm{H}$ Aloulou, 'S Loukil, 'L Sfaihi, 'I Maaloul, 'I Chabchoub, ${ }^{2} \mathrm{D}$ Abid, ${ }^{1} \mathrm{TH}$ Kammoun, ${ }^{1} \mathrm{M}$ Hachicha. ${ }^{1}$ Pediatrics, Hédi Chaker University Hospital, Sfax, Tunisia; ${ }^{2}$ Cardiology, Hédi Chaker University Hospital, Sfax, Tunisia

10.1136/archdischild-2014-307384.718

Introduction Classic infantile pompe disease is an autosomal recessive inherited disorder caused by a deficiency of alpha 1-4 glucosidase, resulting in accumulation of glycogen in skeletal muscle and heart. It's characterised by hypotonia, cardiomegaly and hypertrophic cardiomyopathy, feeding difficulties and respiratory distress, all patients died in the first year of life.

Patients and methods A retrospective study of cases of classic infantile pompe disease collected in the Department of Paediatrics, Hospital Hedi Chaker, Sfax over a period of 7 years (20082013).

Results During the study period we collected 8 cases of the disease. The average age at diagnosis was 3 months and 6 days.

All patients were eutrophic. Hypotonia was noted in all cases, Respiratory distress in seven cases, cyanosis in 4 cases and a systolic murmur in 5 cases. Hepatomegaly was constant, macroglossia was noted in one patient. Chest radiography showed cardiomegaly in all cases. Electrocardiogram, showed electrical signs of left ventricular hypertrophy, wide QRS complex, a shortening of the PR interval was seen in 4 cases. Echocardiography confirmed diagnosis of hypertrophic cardiomyopathy. The dosage of acid maltase activity practiced in 5 patients, showed no enzyme activity. The genetic study of 4 patients showed a mutation in the homozygous state of the GAA gene. Treatment was purely symptomatic involving propranolol, oxygen and antibiotics. All patients died.

Conclusion The fatal evolution of the classic infantile form of Pompe disease is being changed by the advent of enzyme 